\title{
圆 \\ Epidemiological studies of amphistome infections in cattle in the highveld and lowveld communal grazing areas of Zimbabwe
}

\author{
D.M. PFUKENYI ${ }^{1 *}$, S. MUKARATIRWA², A.L. WILLINGHAM ${ }^{3}$ and J. MONRAD ${ }^{3}$
}

\begin{abstract}
PFUKENYI, D.M., MUKARATIRWA, S., WILLINGHAM, A.L. \& MONRAD, J. 2005. Epidemiological studies of amphistome infections in cattle in the highveld and lowveld communal grazing areas of Zimbabwe. Onderstepoort Journal of Veterinary Research, 72:67-86

During the period between January 1999 and December 2000, the distribution and seasonal patterns of amphistome infections in cattle in the highveld and lowveld communal grazing areas of Zimbabwe were determined through monthly coprological examination. Cattle faecal samples were collected from 12 and nine dipping sites in the highveld and lowveld communal grazing areas, respectively. Patterns of distribution and seasonal fluctuations of intermediate host-snail populations and the climatic factors influencing the distribution were also determined by sampling at monthly intervals for a period of 24 months (November 1998 to October 2000) in six dams and six streams in the highveld and in nine dams in the lowveld communal grazing areas. Each site was sampled for relative snail density and the vegetation cover and type, physical and chemical properties of water, and mean monthly rainfall and temperature were recorded. Aquatic vegetation and grass samples 0-1 $\mathrm{m}$ from the edges of the snail habitats were collected monthly to determine the presence or absence of amphistome metacercariae. Snails collected at the same time were individually checked for the emergence of larval stages of amphistomes. A total of 16264 (calves 5418 , weaners 5461 and adults 5 385) faecal samples were collected during the entire period of the study and 4790 $(29.5 \%)$ of the samples were positive for amphistome eggs. For both regions the number of animals positive for amphistome eggs differed significantly between the 2 years, with the second year having a significantly higher prevalence $(P<0.01)$ than the first year. Significantly higher prevalences were found in the highveld compared to the lowveld $(P<0.001)$, for adult cattle than calves $(P<$ $0.01)$, and in the wet over the dry season $(P<0.01)$. Faecal egg output peaked from October to March in both years of the study. Bulinus tropicus, Bulinus forskalii and Biomphalaria pfeifferi were recorded from the study sites. The main intermediate host for amphistomes was $B$. tropicus with a prevalence of infection of $8.5 \%$. However, amphistome cercariae were also recorded in Biom. pfeifferi and $B$. forskalii. Amphistome cercariae were recorded from both the highveld and lowveld areas with peak prevalence during the post-rainy season (March to May). Metacercariae were found on herbage from the fringes of the snail habitats between February and August, with most of the metacercariae concentrated on herbage $0-1 \mathrm{~m}$ from the edges of the habitats.
\end{abstract}

Based on the epidemiological findings a control programme was devised. From this study, large burdens of immature flukes could be expected in cattle during the dry months.

Since adult cattle would be resistant to the pathogenic effects of the migrating immature amphistomes the target for control would be young animals being exposed to the infection for the first time.

* Author to whom correspondence is to be directed. E-mail: dmpfukenyi@hotmail.com

1 Central Veterinary Laboratory, Diagnostic and Research Branch, P.O. Box CY 551, Causeway, Harare, Zimbabwe
2 University of Zimbabwe, Faculty of Veterinary Science, Paraclinical Veterinary Studies, P.O. Box MP167, Mt Pleasant, Harare, Zimbabwe

3 Danish Centre for Experimental Parasitology, Dyrlaegevej 100, DK-1870, Frederiksberg C, Copenhagen, Denmark 
Therefore, the first anthelmintic treatment can be administered in calves in mid June when maximum migration of immature amphistomes starting 3-4 weeks after infection in the early dry season would be expected. A second treatment could be given in late July or early August to remove potentially dangerous burdens of immature flukes acquired later in the dry season. Where resources permit, another strategy would be to treat against the mature flukes in March or April in order to reduce the number of eggs deposited on pastures and the opportunity for infection of the intermediate host snails. To reduce cercarial shedding by the intermediate host snails molluscicides can also be applied during the peak transmission periods (April/May and August/September).

Keywords: Amphistomes, Bulinus tropicus, cattle, communal grazing, epidemiology, Zimbabwe

\section{INTRODUCTION}

The prevalence of amphistomes in domestic ruminants in Africa, particularly cattle, is high (Dinnik 1964). In Africa, Calicophoron microbothrium is one of the most common species occurring in cattle, sheep and goats (Dinnik \& Dinnik 1962; Dinnik 1964; Horak 1971). Other species of amphistomes reported in Southern Africa are Calicophoron calicophorum, Calicophoron phillerouxi, Calicophoron raja, Calicophoron sukari, Calicophoron sukumum, Cotylophoron cotylophorum, Cotylophoron jacksoni, Carmyerius bubalis, Carmyerius parvipapillatus and Carmyerius spatiosus (Dinnik 1961, 1965; Swart \& Reinecke 1962a; Sey 1991). The adult trematodes, found in the rumen and reticulum, are not usually associated with clinical disease (Rolfe \& Boray 1987). Disease is caused when heavy infection with immature flukes results in acute gastroenteritis with high morbidity and mortality, particularly in young animals (Dinnik 1964; Horak 1971; Rolfe \& Boray 1987; Brown 1994). Amphistomosis in domestic ruminants results in serious economic loss to the wool, meat and milk industries (Horak 1967). Field observations in Australia suggest that the disease is often not diagnosed and losses are under-estimated (Rolfe \& Boray 1987) and this may also apply to Zimbabwe.

The distribution of amphistomes is determined by the distribution of their snail intermediate hosts (Dinnik 1964). Bulinus truncatus and Bulinus tropicus are the intermediate snail hosts of $C$. microbothrium in northern and southern Africa respectively (Dinnik \& Dinnik 1962; Swart \& Reinecke 1962a, b; Dinnik 1964; Brown 1994; Mukaratirwa, Kristensen, Siegismund \& Chandiwana 1998; Chingwena, Mukaratirwa, Kristensen \& Chimbari 2002).

The epidemiology and seasonal pattern of infection depends on the species of definitive and intermediate host (Rolfe, Boray, Nichols \& Collins 1991), the system of management and grazing habits of the cattle (Horak 1967; Boray 1969), the biological potential of the snail hosts (Swart \& Reinecke 1962a, b; Dinnik 1964; Horak 1971), the potential of the flukes to infect intermediate and definitive hosts (Dinnik \& Dinnik 1954; Dinnik 1964; Horak 1967), the topography of the snail habitats and the climate (Rolfe et al. 1991).

In Zimbabwe little information is available on the epidemiology and transmission dynamics of amphistomes. The only relevant studies have concentrated on the prevalence of the parasites in cattle (Vassilev 1994, 1999) and on the taxonomic status of the intermediate hosts (Mukaratirwa et al. 1998).

The aim of this study was to determine the epidemiology of amphistomosis in cattle in the highveld and lowveld communal grazing areas of Zimbabwe, and to use this information to recommend appropriate control measures.

\section{MATERIALS AND METHODS}

\section{Study location}

Based mainly on rainfall and temperature, Zimbabwe is divided into agro-ecological regions I, II, III, IV and V (Fig. 1). On the basis of altitude, the country is also divided into three major relief regions, the highveld (1200-2000 m), the middleveld (900$1200 \mathrm{~m}$ ) and the lowveld (below $900 \mathrm{~m}$ ).

The rainy season is from November/December to March/April and the dry season occurs from April/ May to October/November. The respective mean annual rainfall for regions $\mathrm{I}-\mathrm{III}$ is over $1000 \mathrm{~mm}$, 750-1 $000 \mathrm{~mm}$ and $650-800 \mathrm{~mm}$, respectively. Region IV receives a low rainfall of $450-650 \mathrm{~mm}$ that is erratic and subject to periodic droughts. In region $\mathrm{V}$, rainfall is very erratic and less than $500 \mathrm{~mm}$ per annum.

Hills and valleys characterize the topography of the highveld in which streams and rivers are located. Dams, rivers, streams and marshy areas which serve as watering places for livestock, are common in the area. In the lowveld, the topography is generally flat land, with man-made dams serving as watering points for livestock. 


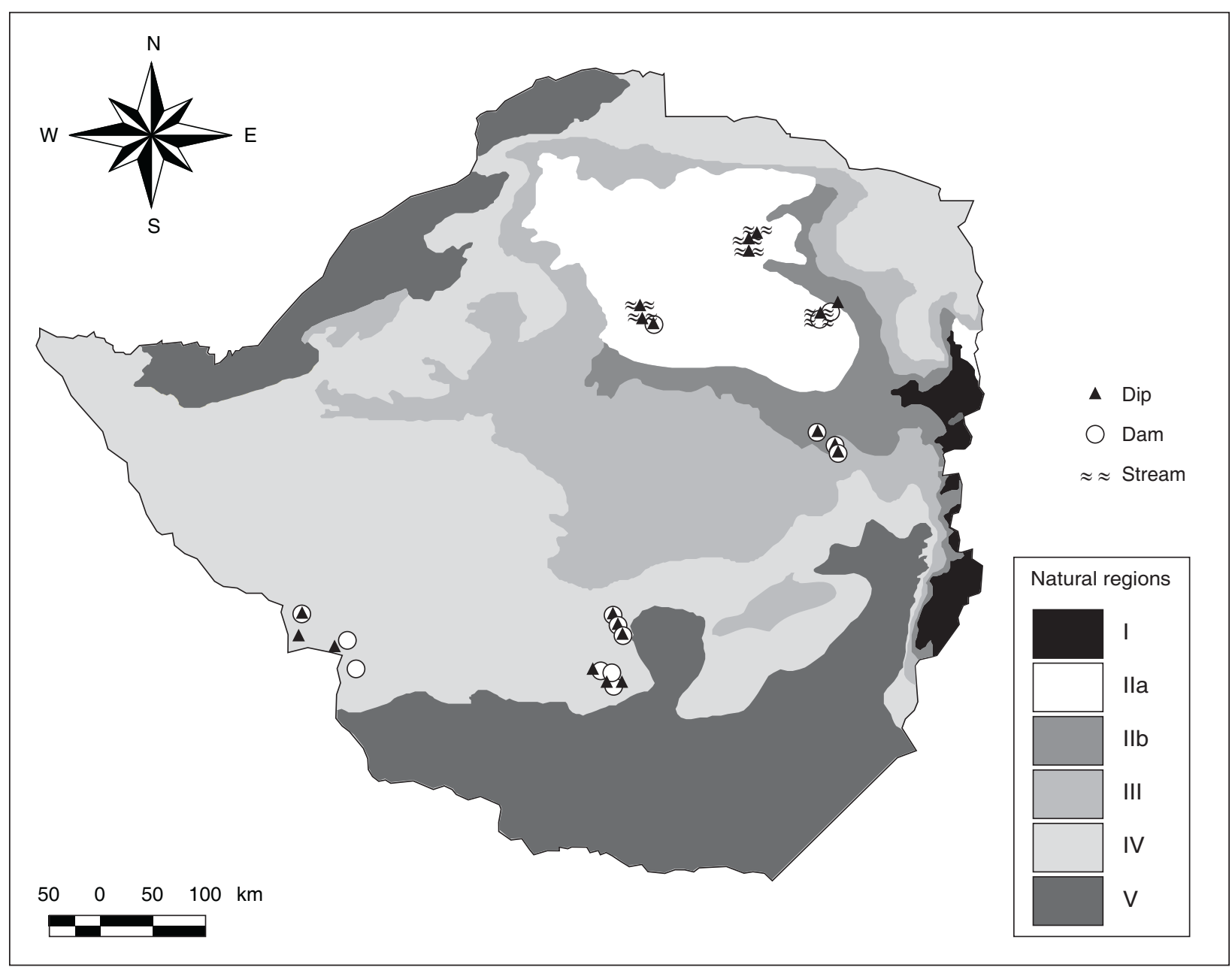

FIG. 1 Location of dips and snail habitats sampled in the different natural regions in the highveld and lowveld communal grazing areas of Zimbabwe

Seven districts were randomly selected within agroecological regions II, III (highveld) and IV (lowveld) (Fig. 1) - four from the highveld and three from the lowveld (Table 1).

\section{Selection of study sites}

Dip tanks were chosen as the study sites owing to the availability of animal handling facilities and access to large populations of cattle. Three dip tanks were randomly selected from each district, giving a total of 21 study sites -12 from the highveld and nine from the lowveld (Table 1). In these areas cattle were dipped weekly during the rainy season and fortnightly during the dry season for the control of ticks.

\section{Animals}

Local indigenous cattle used in the study were Sanga type (a stabilized Bos taurus $\mathrm{x}$ Bos indicus cross), commonly known as "Mashona". Cattle from each of the study sites were categorized into calves (less than 12 months old), weaners (1-2 years old) and adults (over 2 years old). Calves and weaners were further divided into males and females, and adults into dry, lactating and pregnant cows, oxen and bulls. Rectal faecal samples were collected from each category of cattle once every month. The survey covered the period from January 1999 to December 2000.

\section{Snail studies}

In each of the study districts, both drinking and grazing sites were identified, representing habitats of the intermediate host snails (Fig. 1). The sites included dams and streams within the grazing areas. Monthly, from November 1998 to October 2000 each site was sampled for snails, using the scooping method as described by Coulibaly \& Madsen (1990). However, owing to logistical problems, 


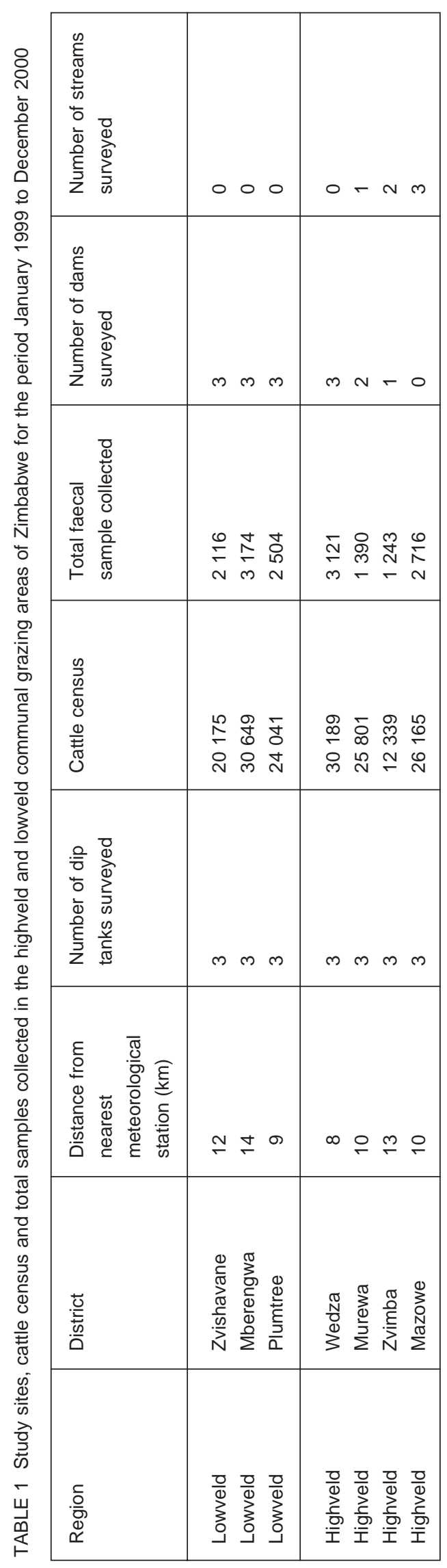


no snails could be collected from some of the sites in March, April, June and August 2000. Each snail collected was identified according to Brown \& Kristensen (1989). To establish the seasonal breeding trends of the snails, the shell height of each was measured before it was returned to its habitat. The snails were categorized into two groups, namely juveniles (4-5 mm), growing and adults (> $5 \mathrm{~mm}$ ); and the sampling method used precluded collection of snails $<4 \mathrm{~mm}$ in length.

All snails sampled at each site were screened for patent amphistome infection, by being placed in individual glass tubes and exposed to fluorescent light for $1 \mathrm{~h}$, followed by darkness for another hour. Emerging cercariae were identified using the key of Frandsen \& Christensen (1984) and the percentage of snails shedding amphistome cercariae was calculated monthly for each site.

Aquatic vegetation and grass samples $0-1 \mathrm{~m}$ from the edges of the snail habitats were collected, and electrical conductivity and $\mathrm{pH}$ of the water recorded monthly at each site. Electrical conductivity and $\mathrm{pH}$ of the water were both measured using a portable electronic conductivity meter (Phillips Heriss, 20.1267) and a portable pH meter (Phillips Heriss, 20.1264), respectively. Collected vegetation samples were examined for the presence of amphistome metacercariae.

\section{Parasitological analysis}

Faecal samples were quantitatively examined for amphistome eggs by the sedimentation technique as described by Boray \& Pearson (1960). The eggs of amphistomes were distinguished from those of Fasciola gigantica on the basis of their colour, amphistome eggs being colourless while those of $F$. gigantica were bright yellow. The prevalence of amphistomes at each site was defined as described by Margolis, Esch, Holmes, Kuris \& Schad (1982).

\section{Meteorological data}

Mean monthly temperatures and mean monthly rainfall data from the meteorological station nearest to each study site were obtained from the recordings by the Department of Meteorology, Belvedere, Harare.

\section{Statistical analysis}

Faecal egg counts were logarithm-transformed $\left[\log _{10}\right.$ (egg count +1$\left.)\right]$ to stabilize the variance before analysis. The effect of age, sex, year, season and location on transformed egg counts was measured by the General Linear Model (GLM) in SPSS (version 8.0). Categories were generated as follows: three for age (calves, < 12 months old, weaners, 1-2 years old and adults $>2$ years old); two for season (wet, November to April and dry, May to October); nine for sex (female calves, male calves, female weaners, male weaners, dry, lactating and pregnant cows, oxen and bulls); and two for locations (highveld and lowveld). Least Significant Difference (LSD) was used as the post-hoc test to measure variances between different categories. Values of $P<0.05$ were considered as significant. The correlation between egg counts and climatic factors (rainfall and temperature) was determined by a linear regression model.

To stabilize for variances, the snail counts were logarithm-transformed $\left[\log _{10}\right.$ (snail count +1$\left.)\right]$. The effect of location, season, year and type of habitat on transformed snail counts was measured by GLM and LSD was used as the post-hoc test to measure variances between different categories. For seasonal analysis of fluctuations in snail populations, the year was divided into four seasons; rainy (December to February), post-rainy (March to May), cold dry (June to August) and hot dry (September to November), as described by Chandiwana, Christensen \& Frandsen (1987). The correlation between snail densities and climatic factors (rainfall and temperature) was determined by a linear regression model.

\section{RESULTS}

\section{Faecal egg counts}

A total of 16264 (calves 5418 , weaners 5461 and adults 5 385) faecal samples was collected during the entire period of the study and $4790(29.5 \%)$ of the samples were positive for amphistome eggs. For both agro-ecological regions the number of animals positive for amphistome eggs differed significantly between the 2 years, with the second year having a significantly higher prevalence $(P<0.01)$ than the first year (Table 2). For both years the highveld had a significantly higher prevalence $(P<$ 0.001) than the lowveld (Table 2).

There were significant differences in the prevalence of amphistome infections among the age categories $(P<0.001)$ of the cattle, with adults having a higher prevalence than weaners and calves-except for weaners and dry cows in year 2 (Table 2). Except for weaners on lowveld in year 1 , female calves and weaners generally had higher prevalences than their male counterparts, but the difference was not 


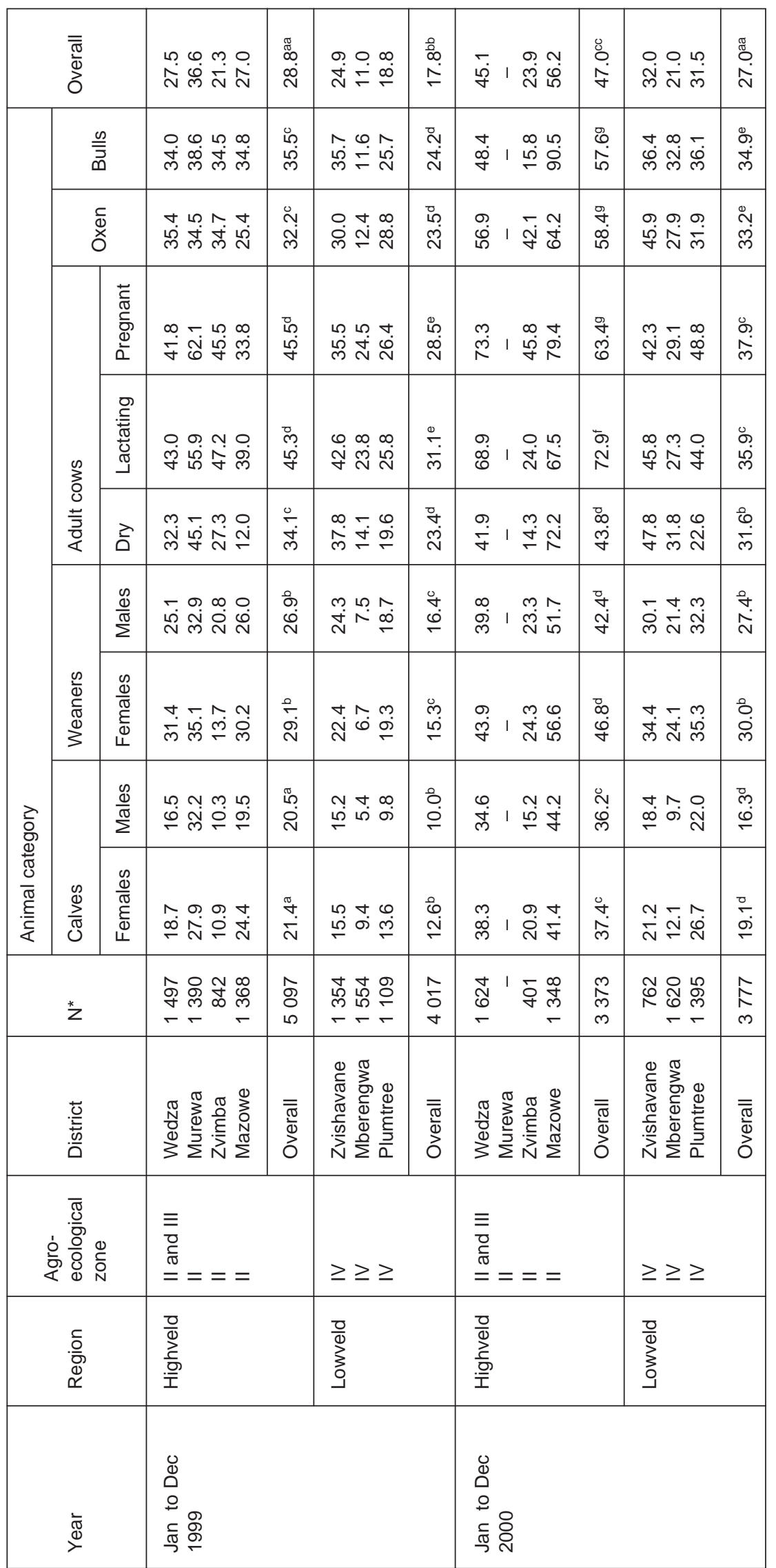


significant (Table 2). Pregnant and lactating cows had significantly higher prevalences $(P<0.01)$ than bulls, oxen and dry cows-except for pregnant cows, oxen and bulls on highveld in year 2 (Table $2)$. In year 2 , oxen and bulls had significantly $(P<$ 0.01 ) higher prevalences than dry cows but no significant differences were recorded among these categories of cattle in year 1 (Table 2).

There were significant differences in the prevalence at different seasons of the year $(P<0.001)$ with the wet season having a significantly higher prevalence than the dry season (Table 3).

The highest monthly egg count recorded during the period of study was 789 eggs per gram of faeces in an adult cow in March 2000. The mean faecal egg count for positive animals combined was 16.4 and 27.6 for the lowveld and highveld, respectively. Calves, weaners and adults had respective mean faecal egg counts of 9.1,19.8 and 36.1. Adults had a significantly higher mean egg count $(P<0.01)$ than the young animals. There was a positive correlation between the faecal egg counts and rainfall $(r=0.68, P<0.001)$.

Faecal egg output was persistent during all the months of the 2-year study period. All age groups showed a similar seasonal trend with respect to both prevalence and mean faecal eggs counts. Random calving occurs in communal grazing areas and therefore the age groups were combined as shown in Fig. 2. The mean faecal egg output and prevalence rose from October to March/April (Fig. 2). Overall, the mean monthly faecal egg output was higher for the highveld than the lowveld (Fig. 2).

\section{Physical and biotic environment of snail habitats}

Between January and March 1999 all the snail habitats (dams and streams) had high water levels with banks flooded and over $75 \%$ vegetation cover. In the lowveld, water levels in the snail habitats were drastically reduced from April, by August/September 1999 the water levels were reduced to less than $20 \%$ compared to the rainy season and vegetation cover was reduced to less than $5 \%$. However, in the highveld water levels declined from June with relatively low levels by October/November. Because of above-normal rainfall received throughout the country during the 1999/2000 rainy season, water levels were relatively high during the dry season compared to those during the previous dry season (Fig. 2).

The $\mathrm{pH}$ values of water in snail habitats sampled ranged from 4.7-8.9 in the highveld and from 5-9.9 in the lowveld. Electrical conductivity of snail habitat water ranged from 100-500 $\mu \mathrm{S}$ in the highveld and from 100-700 $\mu \mathrm{S}$ in the lowveld, being the highest between October and December.

Aquatic vegetation collected at the snail sampling sites included Cyperus spp., Nymphaea caerulea (water lily), Polygonum spp., Potamogeton spp., Phragmites mauritianus (reeds), Typha spp. and Scirpus spp.. Cyperus spp., N. caerulea, Polygonum spp. and Potamogeton spp. were common in both the highveld and lowveld sites, while $P$. mauritianus, Typha spp, and Scirpus spp. were more common in the highveld than the lowveld sites.

\section{Snail abundance and distribution}

Totals of 4082 B. tropicus, 2535 Biomphalaria pfeifferi and 70 Bulinus forskalii were collected from November 1998 to October 2000 in the study sites. While $B$. tropicus was significantly more abundant $(P<0.001)$ in the lowveld than in the highveld, there was no significant difference in the occurrence of Biom. pfeifferi between the two regions. Bulinus forskalii was relatively rare compared to the other snail species and more common in the highveld than in the lowveld.

The total numbers of $B$. tropicus collected in Wedza (highveld) and Zvishavane (lowveld) districts showed an annual variation with significantly higher numbers collected in the first year $(P<0.01)$ than in the second. Biomphalaria pfeifferi showed no significant variations between the two years for both regions (Table 4).

The mean number of snails collected was correlated with the distribution of aquatic vegetation. Bulinus tropicus was positively correlated with Cyperus spp. $(r=0.61, P<0.001), N$. caerulea $(r=0.58, P<0.01)$ and Polygonum spp. $(r=0.51, P<0.01)$ while Biom. pfeifferi was positively correlated with Potamogeton spp. ( $r=0.66, P<0.001)$ and Scirpus spp. $(r=0.41$, $P<0.05)$. The two snail species were negatively correlated $(r=-0.47)$ but the correlation was not significant.

Distribution of the snails according to type of habitat is shown in Table 5. Significantly higher numbers of $B$. tropicus were collected on sites around dams ( $P$ $<0.01$ ) than around streams. In the highveld, Biom. pfeifferi was significantly more common in streams $(P<0.01)$ than in dams.

The seasonal variations in the numbers of $B$. tropicus and Biom. pfeifferi are shown in Table 6. There were no significant seasonal variations in the numbers of snails collected for both species and regions 


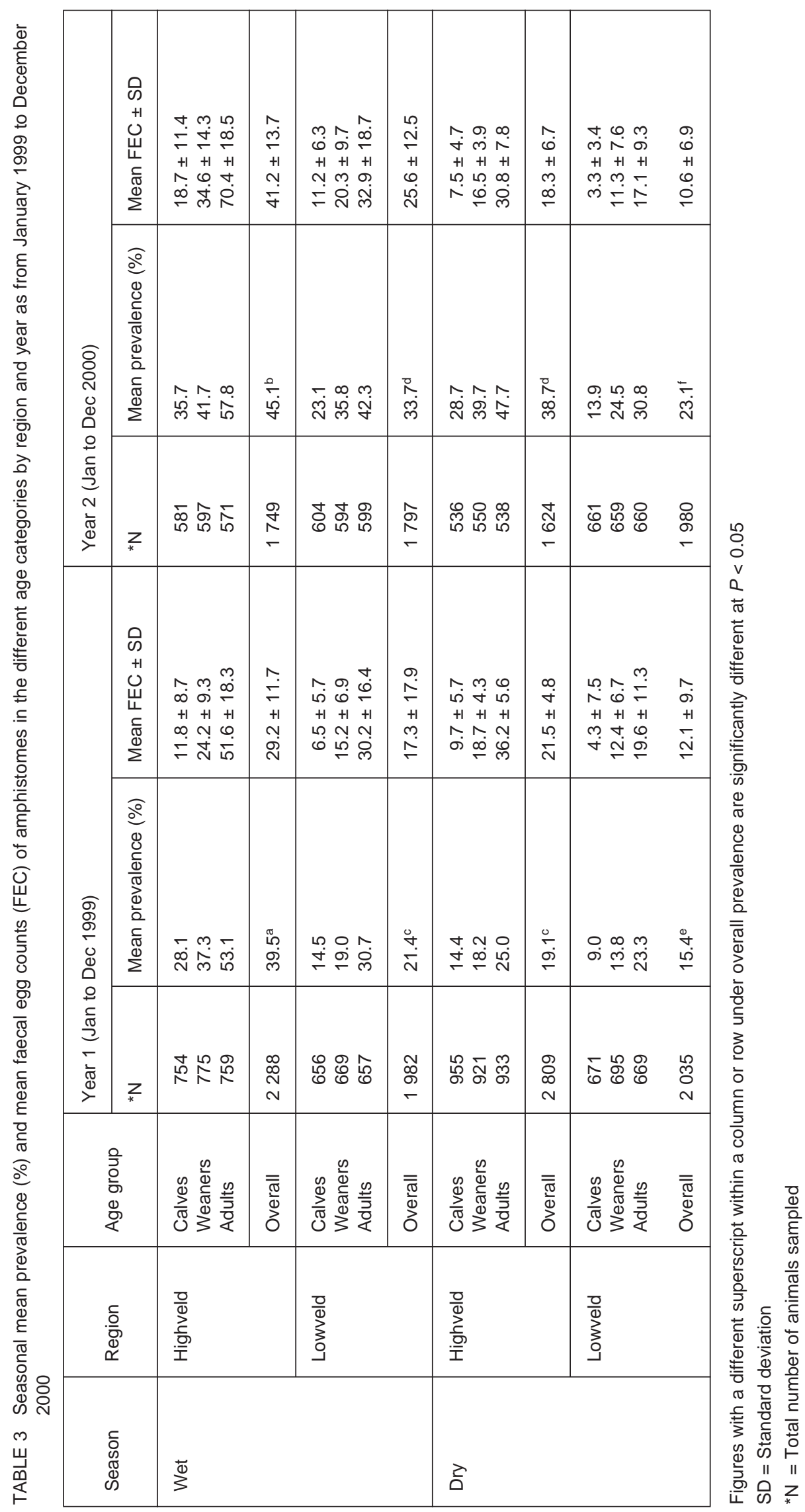



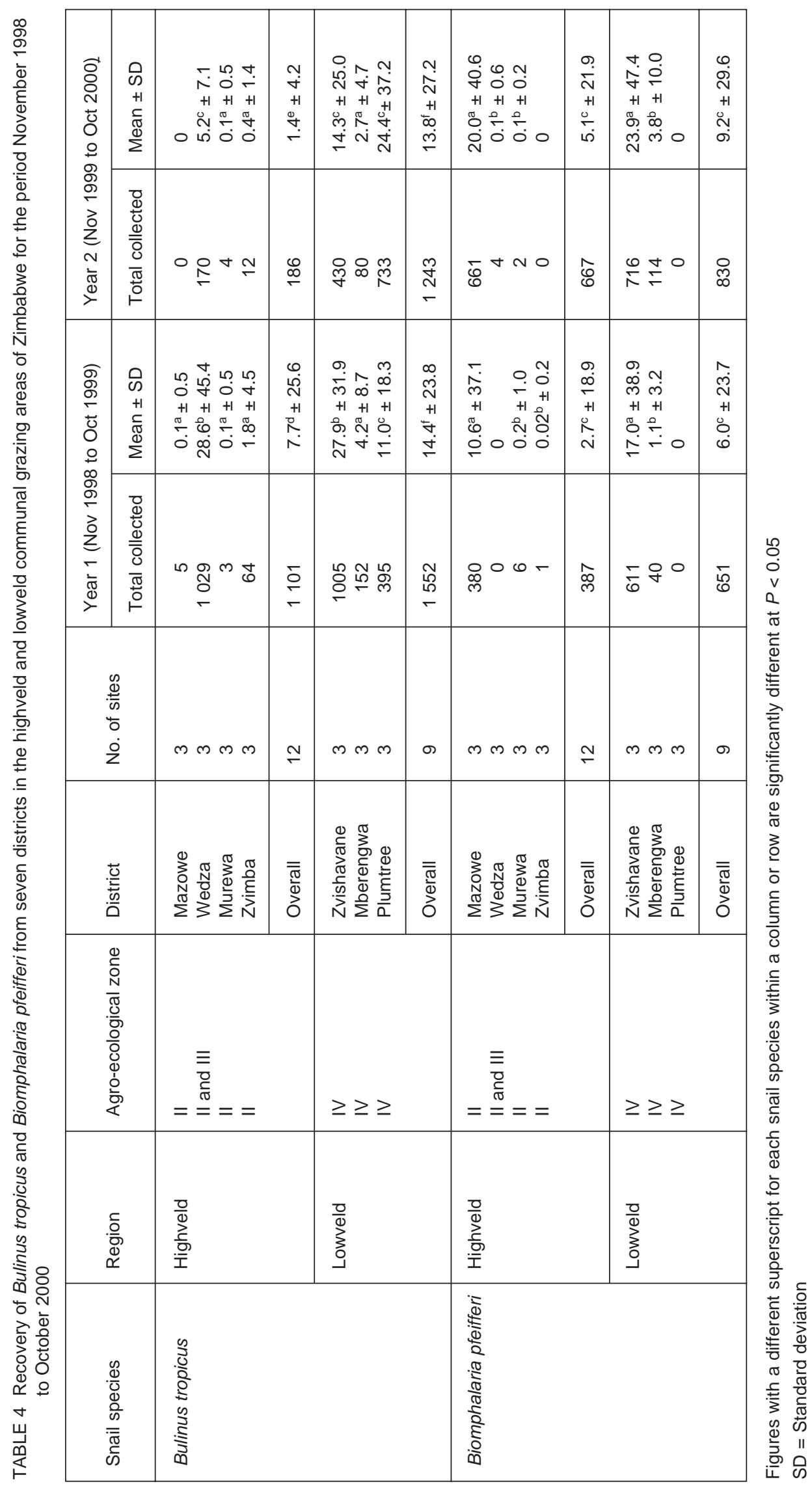


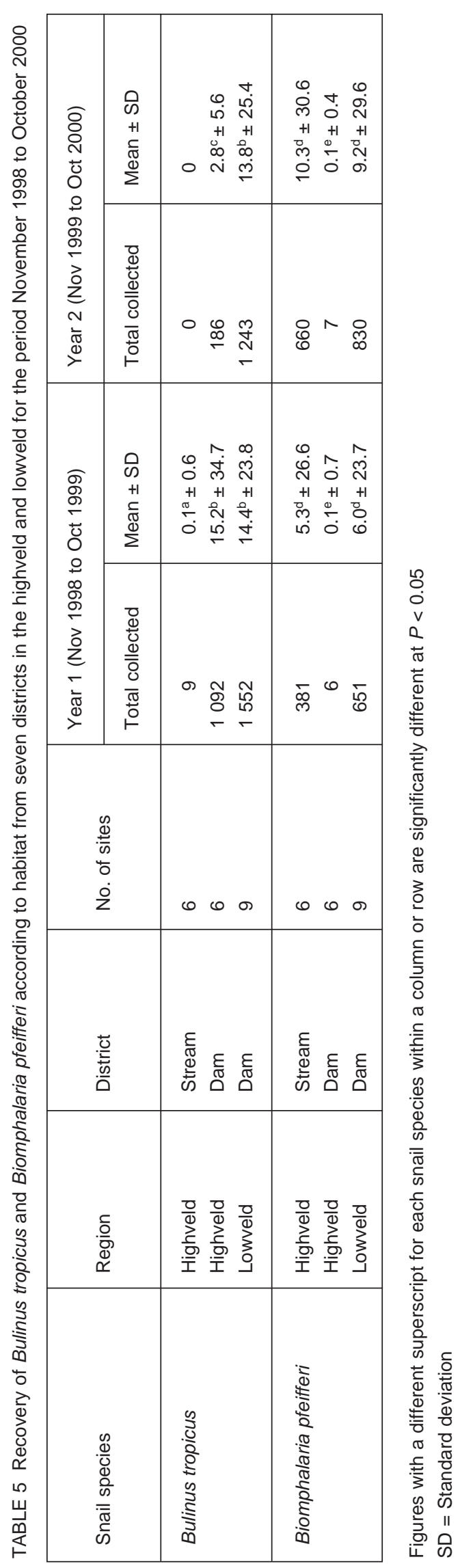



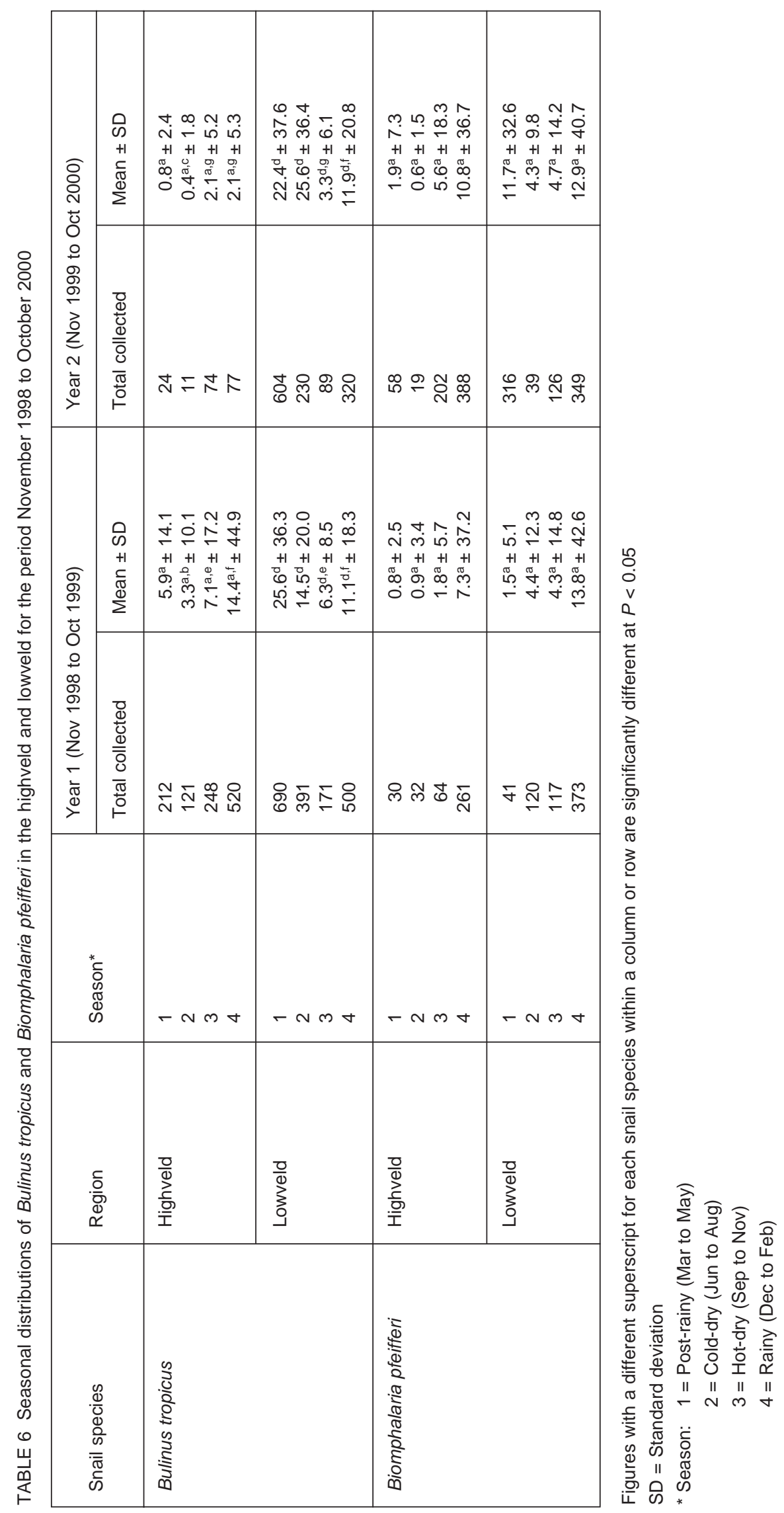

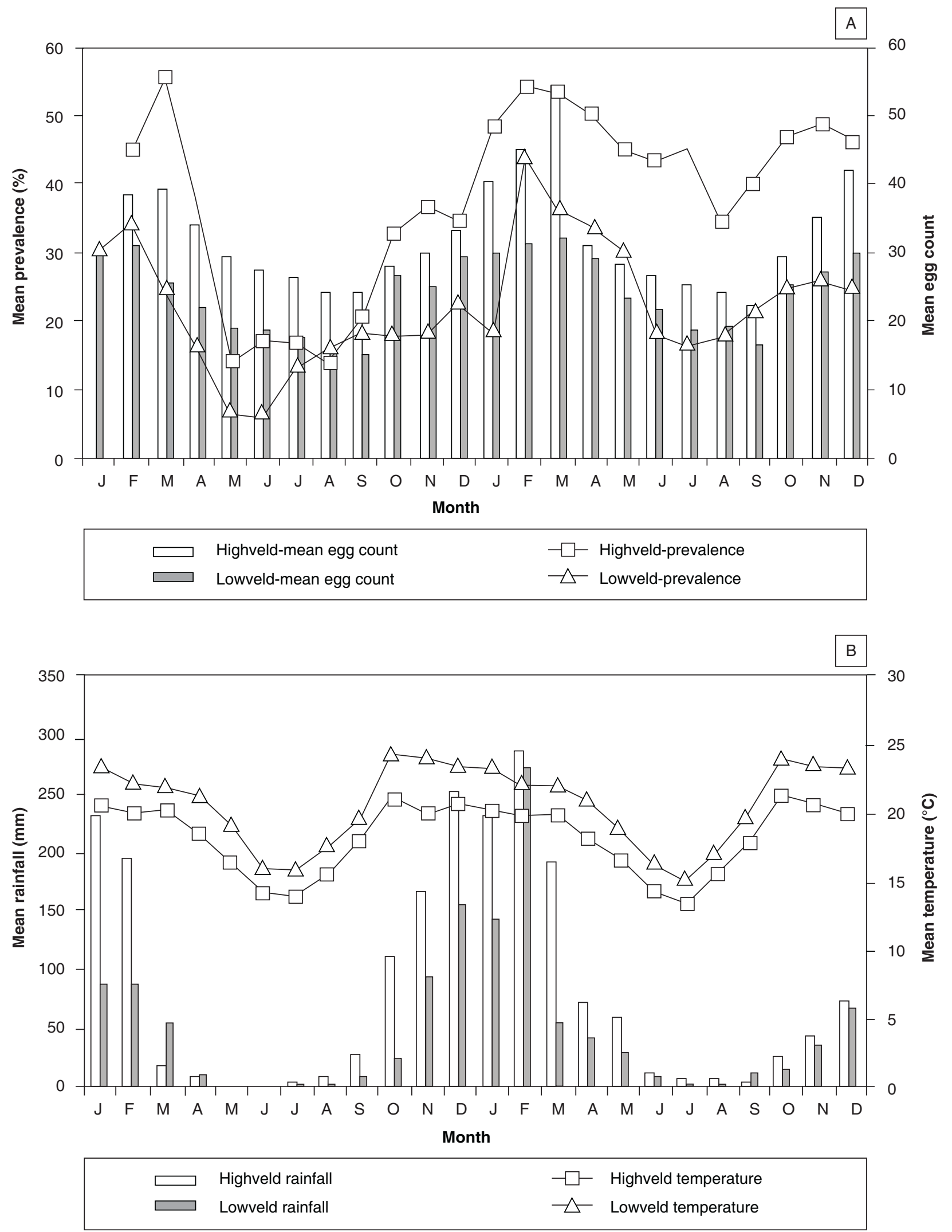

FIG. 2 Mean monthly prevalence (\%) and mean monthly faecal egg counts of amphistomes in cattle (A) and mean monthly rainfall and temperature (B) in the highveld and lowveld communal grazing areas of Zimbabwe sampled for the period January 1999 to December 2000 
within each year. However, in the highveld the number of $B$. tropicus collected during the cold-dry, hotdry and rainy seasons of the first year was significantly higher $(P<0.01)$ than the corresponding seasons of the following year. In the lowveld, a significantly higher number of $B$. tropicus was collect- ed in hot-dry season of the first $(P<0.01)$, than the second year.

Monthly fluctuations of populations of $B$. tropicus and Biom. pfeifferi snails are shown in Fig. 3 and 4. In the highveld, $B$. tropicus (Fig. 3A) peaked in January 1999 with another slight peak in September
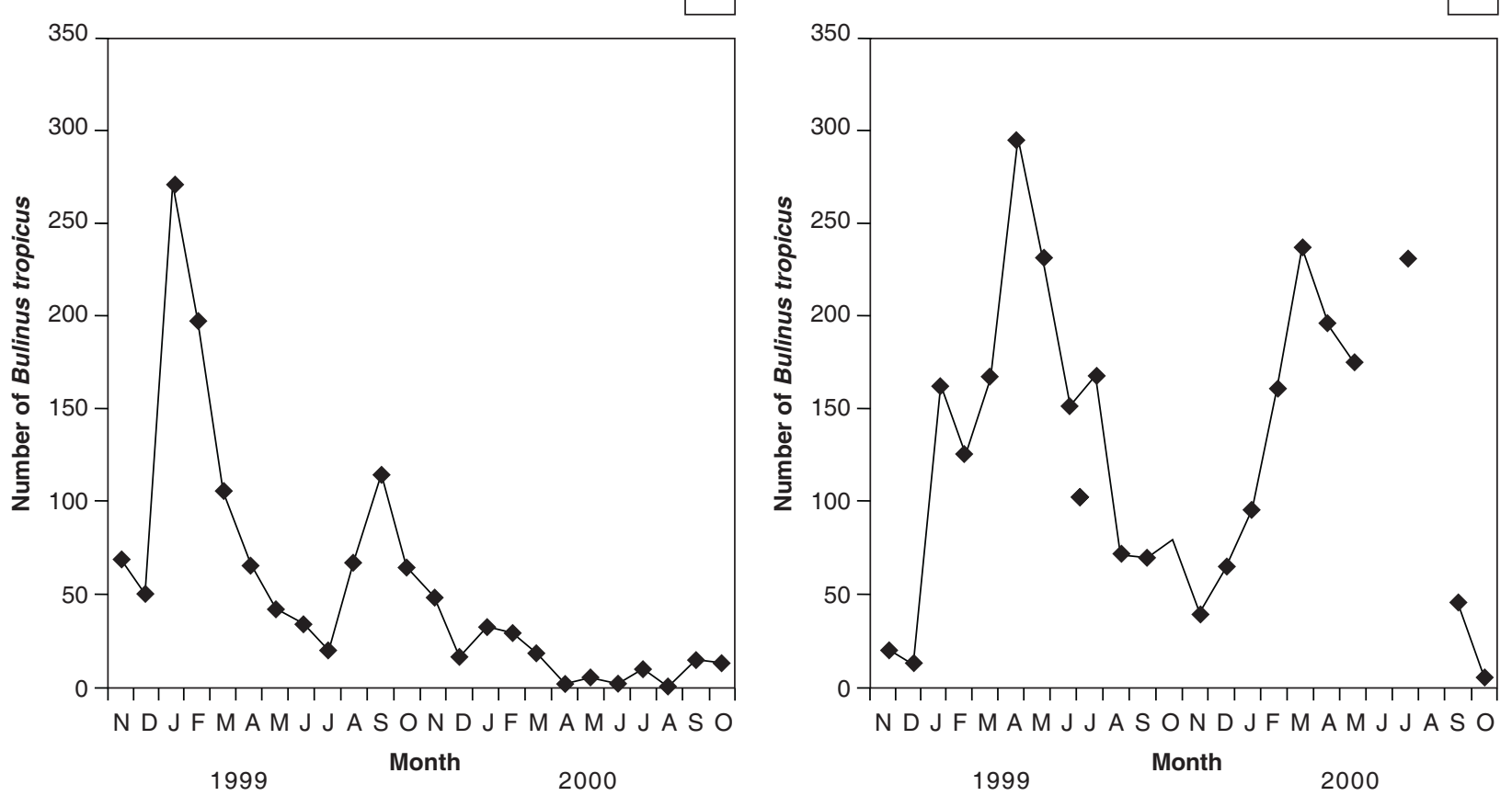

C
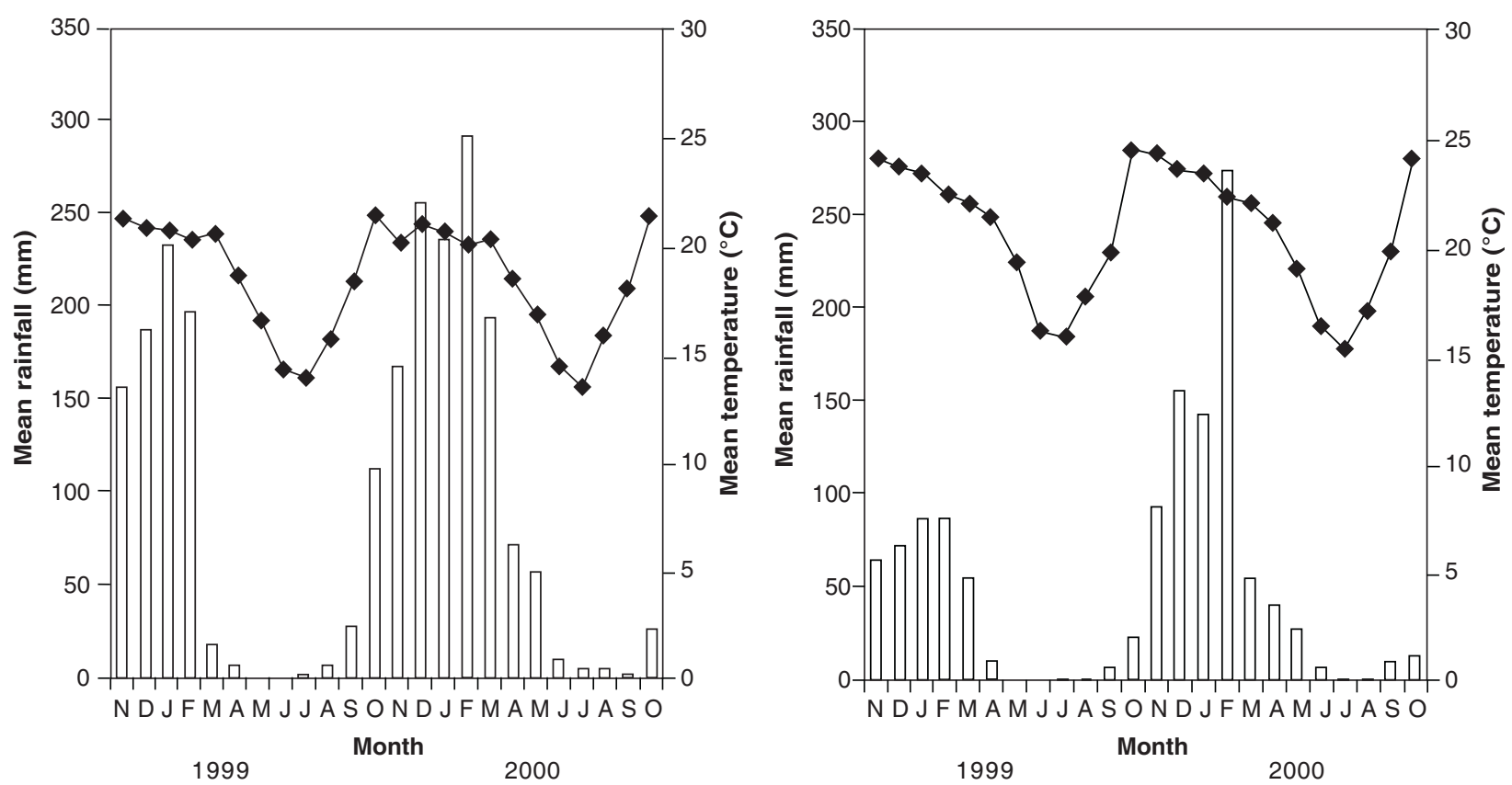

FIG. 3 Monthly variation of Bulinus tropicus in the highveld $(A)$ and lowveld $(B)$, and mean monthly rainfall and temperature in the highveld (C) and lowveld (D) communal grazing areas of Zimbabwe sampled for the period November 1998 to October 2000 
1999, and in the lowveld (Fig. 3B) it peaked in April 1999 and in March 2000.

Biomphalaria pfeifferi (Fig. 4A) had major peaks in December 1998 and January 2000 in the highveld, compared to January 1999 and February 2000 in the lowveld (Fig. 4B). Bulinus forskalii was only recorded between January and March 2000.

Overall, respectively $8.5 \%, 0.3 \%$ and $1.4 \%$ of $B$. tropicus, Biom. pfeifferi and B. forskalii were found shedding amphistome cercariae. The corresponding
A

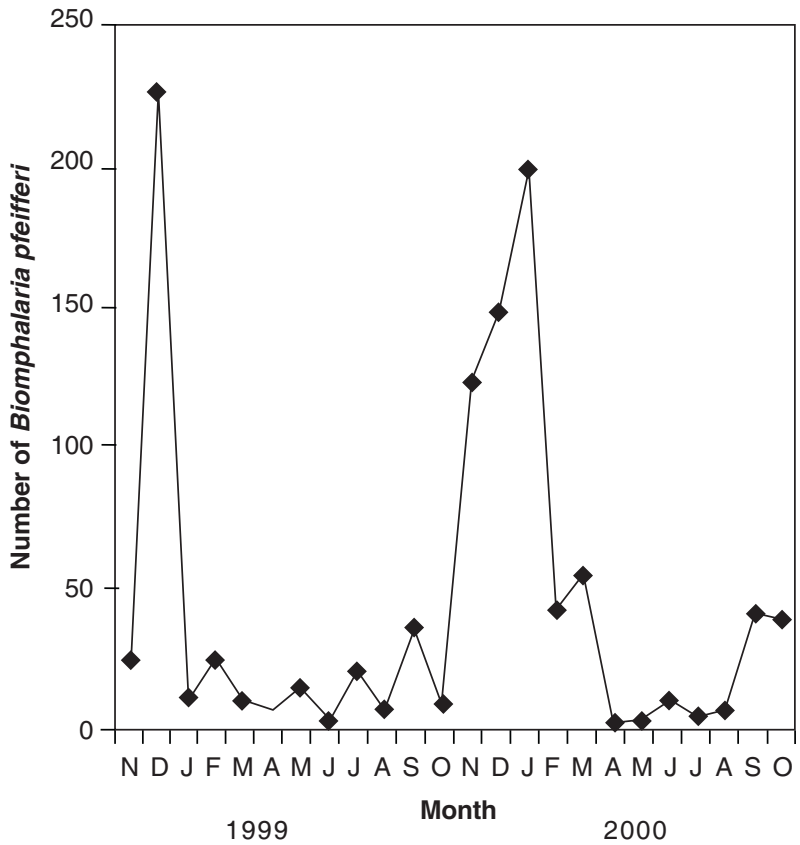

C

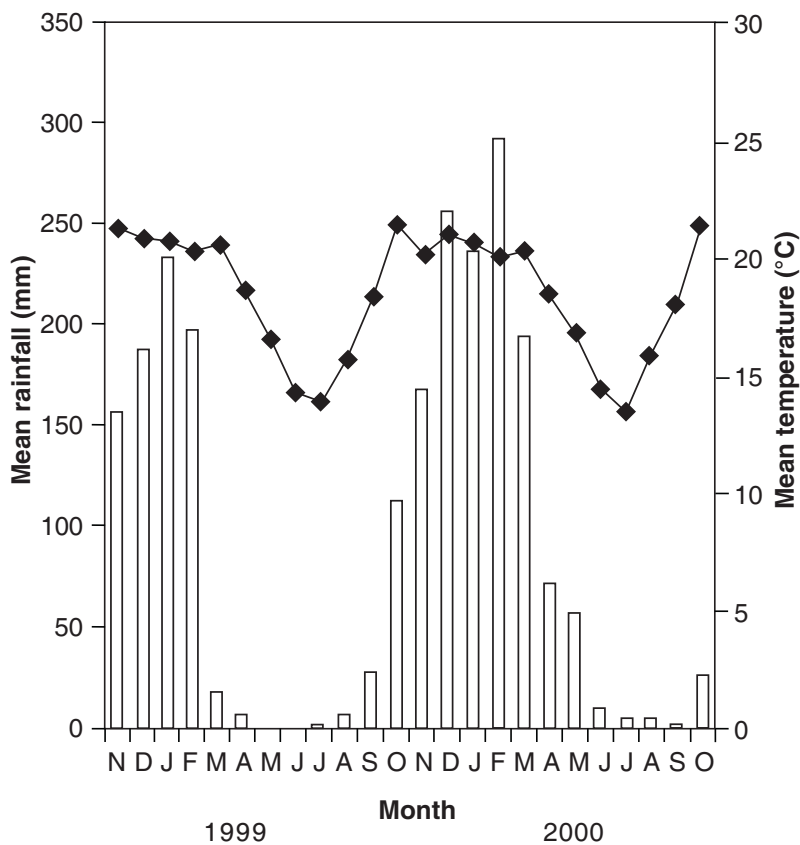

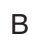

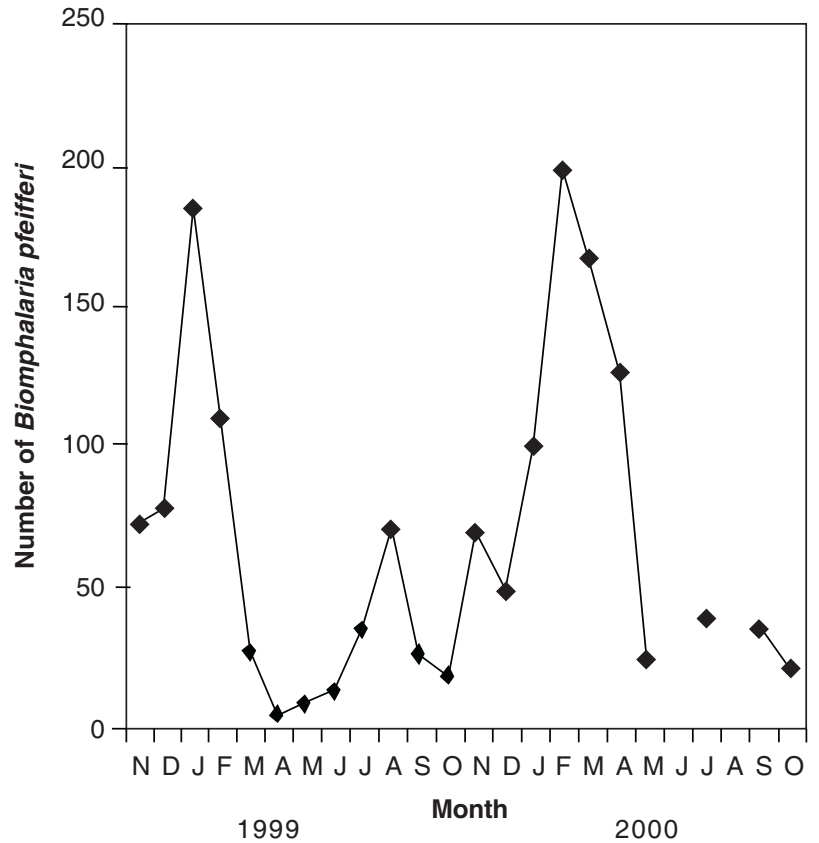

D

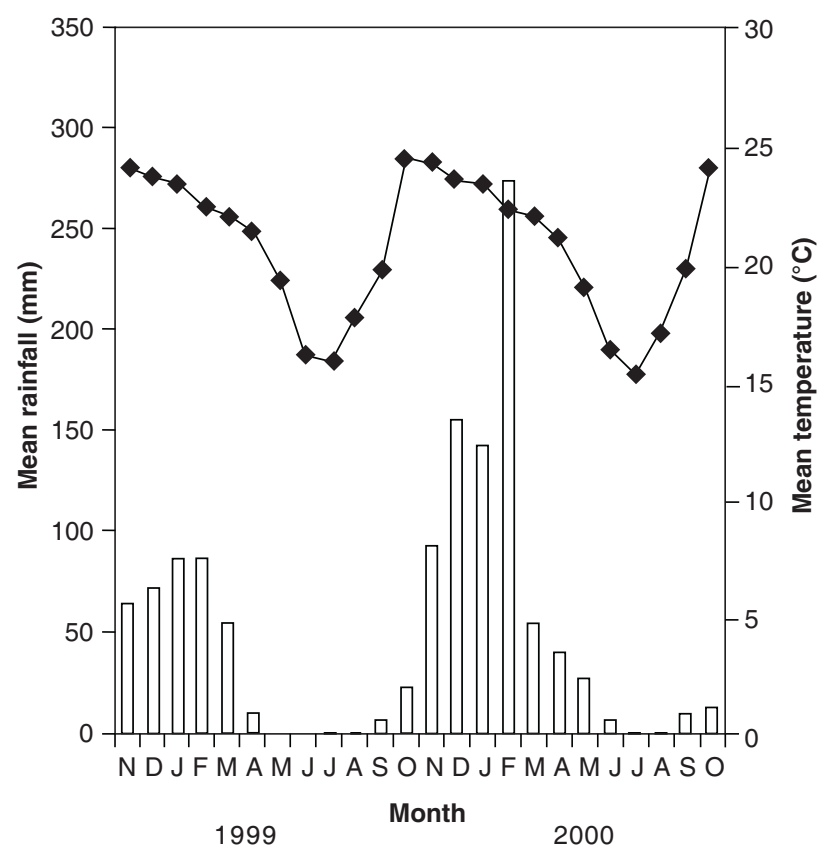

FIG. 4 Monthly variation of Biomphalaria pfeifferi in the highveld (A) and lowveld (B), and mean monthly rainfall and temperature in the highveld (C) and lowveld (D) communal grazing areas of Zimbabwe sampled for the period November 1998 to October 2000 
figures were $4.9 \%, 0.4 \%$ and $1.6 \%$ for the highveld, and $9.9 \%, 0.3 \%$ and $0 \%$ for the lowveld. The prevalence of infection with amphistomes in $B$. tropicus at individual sites ranged from $0-19.5 \%$ in the highveld and $0-20.5 \%$ in the lowveld.

Shedding of amphistome cercariae by $B$. tropicus started in February for both years, peaked in April and May, was low between June and July, peaked again between August and September, with virtually no shedding occurred between October and January (Fig. 5). The number of juvenile snails peaked between April and May for both years and regions. Shedding by $B$. forskalii was only recorded in March 2000 and that by Biom. pfeifferi in February, March and May 2000.

Metacercariae were found on herbage growing in water and $0-1 \mathrm{~m}$ from the edges of the snail habitats between February and August for both years. No grass samples could be collected along the edges of the snail habitats between September and November due to overgrazing.

\section{DISCUSSION}

The presence of amphistomes in communal cattle

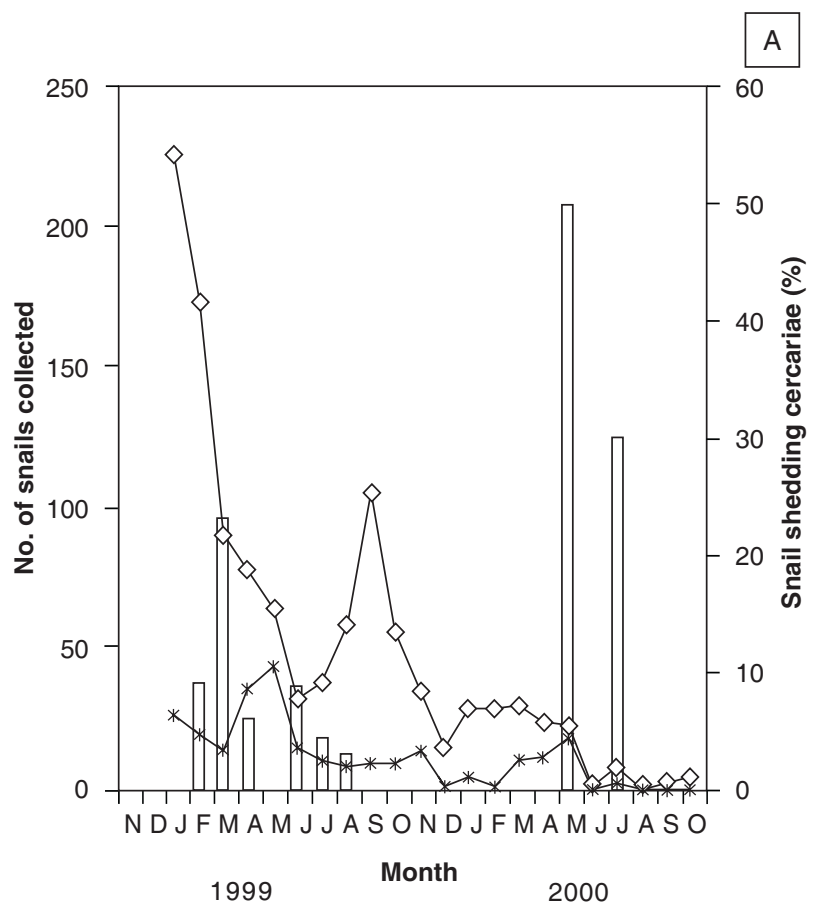

observed in this study is in accordance with earlier reports by Vassilev (1994, 1999). High prevalence of amphistomes in cattle has also been reported from both Africa and other parts of the world (Cheruiyot \& Wamae 1988; Asanji 1989; Sahay, Sahai \& Singh 1989; Howlader, Chowdhury, Taimur \& Jahan 1990; Mahato \& Rai 1992). However, the overall prevalence reported in the present study is lower than previous reports from the highveld of Zimbabwe (Vassilev 1994, 1999), ostensibly owing to differences in study areas. Previous studies were concentrated mainly in the higher rainfall districts of the highveld (Vassilev 1994, 1999) where the prevalence was reported to be higher than in the present study, while in the present study districts in the relatively drier lowveld region were included where the prevalence, as has been anticipated, was lower.

In common with previous studies in Zimbabwe (Chingwena et al. 2002) and also elsewhere in southern Africa (Dinnik 1965), B. tropicus was found to be the main intermediate host of amphistomes in cattle. Fluctuations in the populations of the snail hosts, whether seasonal or longterm over a period of years, have been linked to the basic instability of freshwater habitats (Brown 1994; Mukaratirwa,

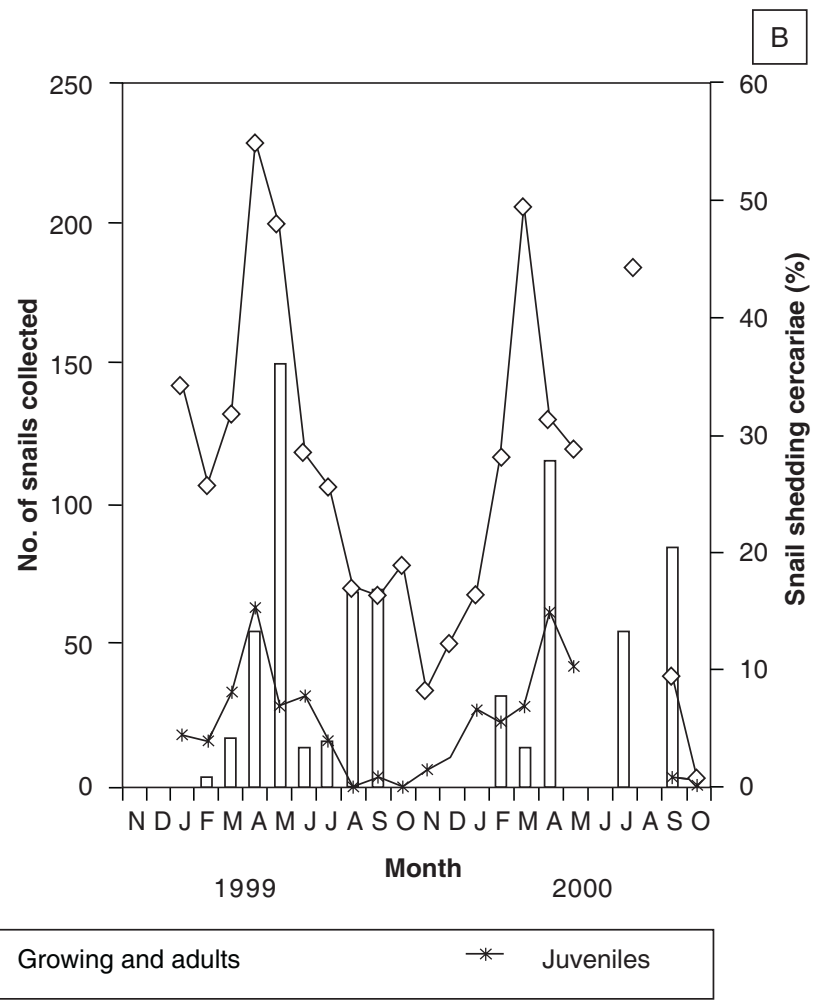

FIG. 5 Monthly variations of juvenile (4-5 mm shell height) and growing/adult (> $5 \mathrm{~mm}$ ) Bulinus tropicus snails and proportion shedding amphistome cercariae in the highveld $(A)$ and lowveld $(B)$ communal grazing areas of Zimbabwe sampled for the period November 1998 to October 2000 
Siegismund, Kristensen \& Chandiwana 1996). From this study, the populations of $B$. tropicus were also found to vary annually especially in the unstable seasonal water bodies of the highveld.

Seven Biom. pfeifferi and only one B. forskalii were found to be shedding amphistomes. Thus, they are probably of low importance for transmission of these parasites. Natural infection of Biom. pfeifferi snails by $C$. sukari has also been reported in Kenya and Zambia (Dinnik 1965). Wright, Southgate \& Howard (1979) and Okafor, Mbata \& Anosike (1988) reported natural infection of $B$. forskalii by Carmyerius species in Zambia and by Paramphistomum cervi in Nigeria.

A higher prevalence of amphistome infection in cattle was recorded in the highveld districts located in agro-ecological regions II and III than in the districts in the lowveld (Table 2). Bulinus tropicus snails are extremely adaptable and may be found in streams, ponds, pools, water troughs, dams, marshes, irrigation canals and fountains (Dinnik 1964). In the highveld dams, rivers and seasonal streams and pools and marshy areas, which serve as common watering and grazing grounds for livestock, are more common and more widely distributed than in the lowveld, where man-made dams and a few seasonal pools serve as watering points. Hence, as supported by the results of this study, the chance of cattle becoming infected can be expected to be higher in the highveld, characterized by wet/swampy grazing areas where distribution of snail habitats is widespread, than in the lowveld, with dry-land grazing and focal distribution of snail habitats.

Species-diversities of freshwater snails occurring at a given locality are usually associated with aquatic or subaquatic leafy plants (Brown 1994), and there may be a symbiotic relationship between snails and aquatic macrophytes that has evolved over a long period of time (Thomas 1982). Butler \& Yeoman (1962) found large numbers of $B$. tropicus in the tangle of vegetation matter at the base of clumps of Cyperus digitatus and concluded that the presence of this plant is of value in predicting Bulinus spp. habitats in the areas they studied in Tanzania. In Sudan, Madsen, Daffalla, Karoum \& Frandsen (1988) found a positive association between Biom. pfeifferi and Potamogeton spp. Likewise, the numbers of snails collected in this study were found to be correlated with the abundance of certain plant species: B. tropicus with Cyperus spp., Polygonum spp. and N. caerulea; and Biom. pfeifferi with Potamogeton and Scirpus species. Although the relationships need not necessarily be predictive, these plants may be useful indicators of snail abundance within the studied areas. However, conductivity and $\mathrm{pH}$ values were consistently within the tolerance levels of freshwater snail species (Brown 1994) and did not seem to markedly influence the observed numerical trends of the snail populations.

The highest prevalence of amphistome infection occurred in older animals, with calves having the lowest prevalence. This observation agrees with earlier findings in Zimbabwe (Vassilev 1994, 1999) and in other parts of the world (D'Souza, Jagannath \& Abdul-Rahman 1988; Okafor et al. 1988; Howlader et al. 1990; Mahato \& Rai 1992). According to Horak (1967, 1971), adult amphistomes live longer in cattle than in sheep. Egg production is maintained at a high level and it was concluded that cattle are better-adapted final hosts of amphistomes than are other susceptible animal species. Cattle develop some degree of natural resistance to the flukes during the most pathogenic stage of the life cycle, suggesting an association that assures the survival of the parasite (Horak 1967, 1971). The occurrence of clinical amphistomosis has been reported in young cattle and sheep, while adult animals grazing the same pastures exhibited no clinical effects of the disease despite continued presence of worm eggs in the faeces (Butler \& Yeoman 1962; Boray 1959, 1969; Rolfe et al. 1991). The development of resistance in cattle after a primary infection and later challenged with C. microbothrium has been experimentally demonstrated in 1year-old steers (Mavenyengwa 2004). The results showed that cattle upon reinfection with amphistomes could mount resistance involving the accumulation of tissue eosinophils and mucosal mastocytes as the major cellular effector systems. The resistance mechanisms involved in amphistome rejection in challenged cattle are directed against immature fluke establishment in the small intestines, while mature parasites from the primary infection become immunologically privileged in the rumen (Mavenyengwa 2004). Therefore, the high prevalence rate and faecal egg counts observed in older animals in this study are probably the results of previous exposure having led to immunity to the pathogenic effects of the immature flukes, moderating the intensity of re-infection and, at the same time, maintaining high levels of egg production by the mature parasites.

From the results of faecal egg output in this study, all ages of cattle harboured mature amphistomes but the adult animals had the highest egg output. Evidently, from this and other studies (Boray 1959; Horak 1971; Rolfe \& Boray 1987; Rolfe et al. 1991), 
adult cattle act as reservoirs of infection and contaminate the environment with eggs, thus predisposing young animals to acute and subacute amphistomosis in areas where the intermediate snail hosts are prevalent.

According to Horak $(1967,1971)$, outbreaks of acute amphistomosis due to infection with immatures in cattle in South Africa are usually confined to the drier months (March to October in South Africa), which fall between autumn and spring, as supported by other reports on this situation in Tanzania (Butler \& Yeoman 1962), Nigeria (Okafor et al. 1988) and Sierra Leone (Asanji 1989). Outbreaks in sheep in Australia (Boray 1969) occurred during dry summer months when stock were forced to graze swampy pasture. Clinical disease in tracer calves was observed 16-24 weeks after the onset of heavy seasonal rainfall when the calves grazed pastures previously inundated with water (Rolfe et al. 1991). In the present study, the prevalence and faecal egg production was high during the period October to March/April. In South Africa, amphistome faecal egg counts in goats were also reported to follow a seasonal pattern, with an increase in faecal egg counts in the rainy season, during the warmer months of October to March (Vatta \& Krecek 2002).

During the wet season there are abundant grazing and alternative sources of drinking water. Therefore, this reduces the need for animals to graze near, and to drink from, particularly permanent water holes. Also during the rainy season animals are pastured away from wet low-lying marshy areas and permanent pools, especially in the communal areas where most of the land will be under crop production. In addition, snail habitats and pastures are constantly flooded, and thus, snails and the free-living stages of the parasites are flushed out and disseminated over a large area. As a result, only light infections are likely to be acquired during the wet season. However, faecal egg counts are high during this period due to mature infections acquired during the previous dry season.

Towards the end of the rainy season (March/April) eggs of amphistomes dropped on pasture survive to infect the new generation of snails which start to grow at the end of the rainy and beginning of the dry seasons. Shedding of amphistome cercariae by the main snail intermediate host, $B$. tropicus, occurred in February for both years of the study, peaked in April/May and peaked again at much lower levels in August/September, with virtually no shedding between October and January. Therefore, from this study amphistome metacercariae are available on vegetation surrounding snail habitats from February to October, with peak concentrations in April/May and August/September. During the dry season cattle are allowed free ranching, especially in communal areas. Therefore, the observed peak cercarial shedding during the early to mid-dry season coincides with a reduction of the available grazing areas and sources of drinking water for cattle. This therefore increases the need for cattle to graze near and drink from permanent water sources.

From April to September/October, cattle are therefore ingesting metacercariae leading to a build-up of immature parasites and this new infection matures progressively as more metacercariae are ingested with receding water levels. At the same time, due to aging, natural attrition of mature amphistomes acquired during the previous dry season occurs. This would account for the low faecal egg production observed in this study during the dry season and also for reports by Vassilev (1999) of acute outbreaks of amphistomosis in the country during the dry months.

The prepatent period of amphistomes in cattle is 56 days (Horak 1967) to 89 days (Dinnik \& Dinnik 1962) and the new infections acquired during the early to mid-dry season mature progressively as more metacercariae are ingested with receding water levels until end of September to early October. Between September and November, transmission is probably very low as no vegetation samples could be collected around the snail habitats during this period due to overgrazing. Maturing of all individual amphistomes, including those that were delayed in development, takes 5-9 months in cattle (Brown 1994). Therefore, 5-9 months after ingestion all immature parasites become fully mature, which would account for the high faecal egg production determined in this study from August to March. The investigations described in this paper thus give a picture of the epidemiological cycle of amphistomes and the main intermediate snail host, $B$. tropicus, in the communal grazing areas of the lowveld and highveld of Zimbabwe that were studied (Fig. 6).

A forecasting system based on epidemiological factors can help to integrate control strategies in a cost-effective manner (Rolfe et al. 1991). In normal seasons, the time of cercarial release by the intermediate host snails can be used to predict when it would be necessary to take control measures (Rolfe et al. 1991). However, this factor should be coupled with rainfall received, as this would have a bearing on pasture availability. Thus, the control of amphistomosis should involve both pasture management and dosing with anthelmintics (Rolfe et al. 1991). 


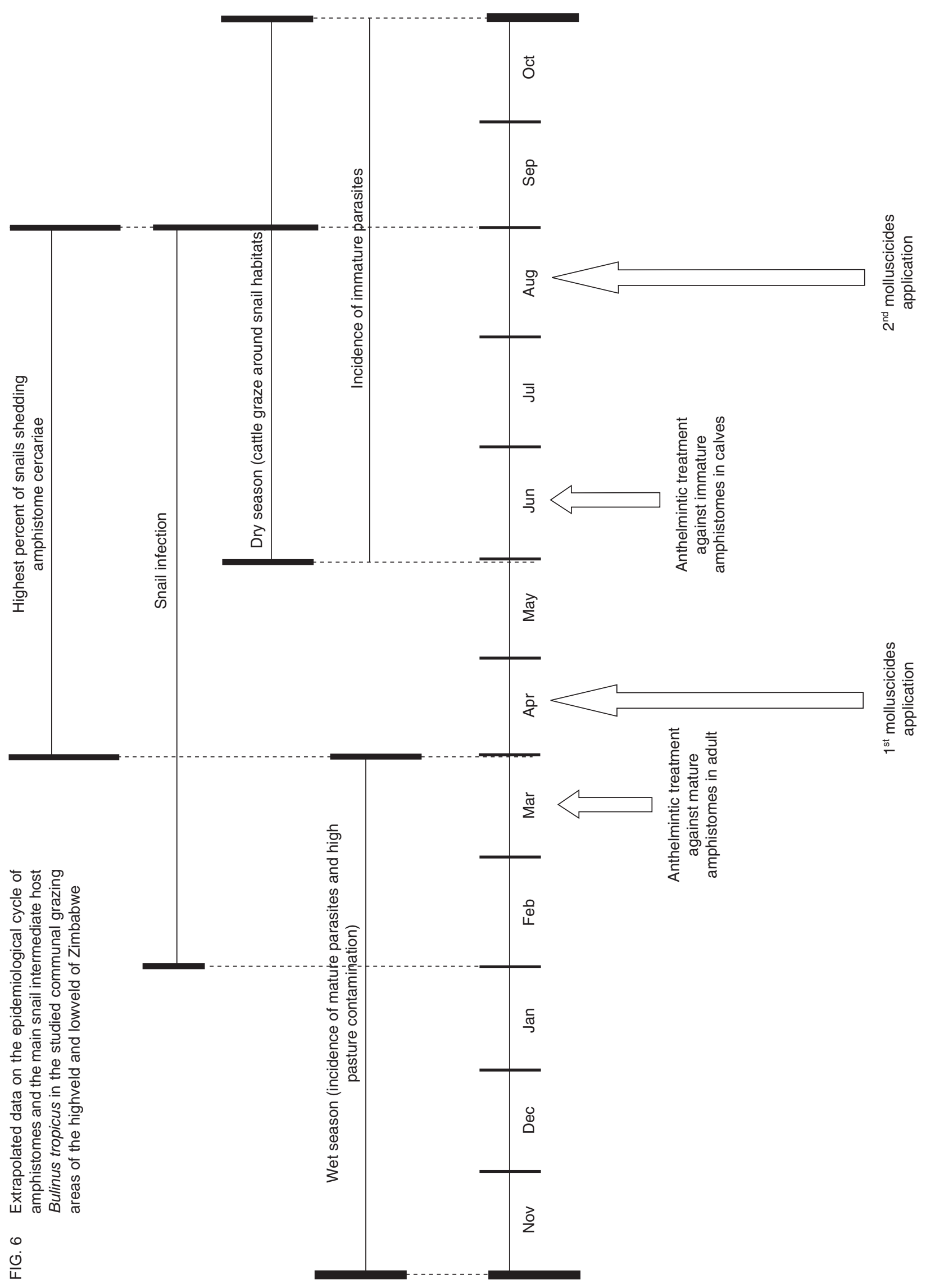


From this study, large burdens of immature flukes could be expected in cattle during the dry months (Fig. 6). Since adult cattle would be resistant to the pathogenic effects of the migrating immature amphistomes the target for control would be young animals being exposed to the infection for the first time. Therefore, the first anthelmintic treatment can be administered in calves in mid June (Fig. 6) when maximum migration of immature amphistomes starting 3-4 weeks after infection in the early dry season would be expected. A second treatment could be given in late July or early August to remove potentially dangerous burdens of immature flukes acquired later in the dry season.

Although anthelmintic treatment of mature amphistome infections is of no direct benefit to the animal it may be prophylactic in effect in that it serves to reduce or eliminate the source of infection for the intermediate snail hosts (Horak 1971). Eggs of amphistomes dropped on pasture towards the end of the rainy season (March/April) survive to infect the new generation of snails. Where resources permit, another strategy would be to treat against the mature flukes in March (Fig. 6) in order to reduce the number of eggs deposited on pastures and the opportunity for infection of the intermediate host snails.

Control of snails can also be done through habitat management in the form of vegetation clearance which is potentially effective both through reducing the availability of feed for the snails and also by enhancing water flow rates during the rainy season (Woolhouse \& Chandiwana 1990). However, this method of control is difficult and virtually almost impossible in the highveld where the distribution of the snail habitats is widespread. Probably in the lowveld, where the snail habitats are focal, control of these snails by habitat management might be effective if the villagers work as a team.

Chemical control through application of molluscicides can also be carried out. However, a good molluscicide should be effective, selective, stable, inexpensive and easy to use and none of the currently available molluscicides satisfy all these criteria as they have an important impact on non-targeted organisms. In addition, due to rapid recovery of these snail populations (Woolhouse \& Chandiwana 1990; Brown 1994) during brief periods of favourable conditions, recolonization should be expected and this may necessitate regular molluscicide application, which may prove to be difficult for resource-poor communal farmers. Where possible and extremely necessary, for optional results this type of control should be done during the peak transmission peri- ods (April/May and August/September) to reduce cercarial shedding (Fig. 6). Control by residual molluscicides may be more viable in the long term. However, this control strategy may be impractical in the highveld of Zimbabwe due to widespread distribution of the snail habitats.

Whatever control strategy is employed in the regions studied, it is imperative that it should be village-based as cattle in communal areas are grazed together and there is no benefit for only a few farmers to carry out the recommended control measures. The anthelmintic treatment should be organised and preferably done at the same time within a village. In communal areas cattle are dipped weekly during the rainy season and fortnightly during the dry season for the control of ticks and dip tank facilities where all animals are gathered during dipping sessions could, therefore, be used for organised worm control. However, simple user-friendly extension material to make cattle owners aware of this parasite and its control should be produced and disseminated to them and the extension staff.

\section{ACKNOWLEDGEMENTS}

We thank the Danish International Development Agency (DANIDA) as part of the ENRECA Livestock Helminth Research Project, who sponsored the studies described here. Grateful thanks are due to the laboratory staff of the Parasitological Section, Department of Paraclinical Veterinary Studies and the Central Veterinary Laboratory for their able assistance with the helminthological work. The Department of Meteorology, Belvedere, Harare is thanked for kindly providing climatic data of the studied districts.

\section{REFERENCES}

ASANJI, M.F. 1989. Paramphistomiasis of cattle in Sierra Leone and seasonal fluctuations in its prevalence. Bulletin of Animal Health and Production in Africa, 37:327-331.

BORAY, J.C. 1959. Studies on intestinal amphistomosis in cattle. Australian Veterinary Journal, 35:282-287.

BORAY, J.C. 1969. Studies on intestinal amphistomosis in sheep due to Paramphistomum ichikawai, Fukui 1922. Veterinary Medical Review, 4:290-308.

BORAY, J.C. \& PEARSON, I.G. 1960. The anthelmintic efficiency of tetrachloro-difluoroethane in sheep infested with Fasciola hepatica. Australian Veterinary Journal, 36:331-337.

BROWN, D. 1994. Freshwater snails of Africa and their medical importance, $2^{\text {nd }}$ ed. Department of Zoology, Natural History Museum. London: Taylor \& Francis Ltd.

BROWN, D.S. \& KRISTENSEN, T.K. 1989. A field guide to African freshwater snails, southern African species. Copenhagen: Danish Bilharziasis Laboratory. Publication no. 383. 
BUTLER, R.W. \& YEOMAN, G.H. 1962. Acute intestinal paramphistomiasis in Zebu cattle in Tanganyika. Veterinary Record, 74:227-231.

CHANDIWANA, S.K., CHRISTENSEN, N.Ø. \& FRANDSEN, F. 1987. Seasonal patterns in the transmission of Schistosoma haematobium, S. mattheei and S. mansoni in the highveld region of Zimbabwe. Acta Tropica, 44:433-444.

CHERUIYOT, H.K. \& WAMAE, L.W. 1988. Incidence of bovine paramphistomiasis in Kenya. Bulletin of Animal Health and Production in Africa, 36:55-57.

CHINGWENA, G., MUKARATIRWA, S., KRISTENSEN, T.K. \& CHIMBARI, M. 2002. Larval trematode infections in freshwater snails from the highveld and lowveld areas of Zimbabwe. Journal of Helminthology, 76:283-293.

COULIBALY, G. \& MADSEN, H. 1990. Seasonal fluctuations of intermediate hosts of schistosomes in two streams in Bamako, Mali. Journal of African Zoology, 104:201-212.

DINNIK, J.A. 1961. Paramphistomum phillerouxi sp. nov. and its development in Bulinus forskalii. Journal of Helminthology, 35:69-90.

DINNIK, J.A. 1964. Intestinal paramphistomiasis and Paramphistomum microbothrium Fischoeder in Africa. Bulletin of Epizootic Diseases in Africa, 12:439-454.

DINNIK, J.A. 1965. The snail hosts of certain Paramphistomatidae and Gastrothylacidae (Trematoda) discovered by the late Dr P.L. le Roux in Africa. Journal of Helminthology, 39: 141-150.

DINNIK, J.A. \& DINNIK, N.N. 1954. The life cycle of Paramphistomum microbothrium Fischoeder, 1901. Parasitology, 44: 225-299.

DINNIK, J.A. \& DINNIK, N.N. 1962. The growth of Paramphistomum microbothrium Fischoeder to maturity and its longevity in cattle. Bulletin of Epizootic Diseases in Africa, 10:27-31.

D'SOUZA, P.E., JAGANNATH, M.S. \& ABDUL-RAHMAN, S. 1988. Prevalence of gastrointestinal parasitism in cows and buffaloes. Indian Journal of Animal Sciences, 58:748-752.

FRANDSEN, F. \& CHRISTENSEN, M.O. 1984. An introductory guide to the identification of cercariae from African freshwater snails with special reference to cercariae of trematode species of medical and veterinary importance. Acta Tropica, 41:181-202.

HORAK, I.G. 1967. Host parasite relationships of Paramphistomum microbothrium in experimentally infested ruminants with particular reference to sheep. Onderstepoort Journal of Veterinary Research, 34:451-540.

HORAK. I.G. 1971. Paramphistomiasis of domestic ruminants. Advances in Parasitology, 9:33-72.

HOWLADER, M.M.R., CHOWDHURY, S.M.Z.H., TAIMUR, M.J.F.A. \& JAHAN S. 1990. Fluke infestations of cattle in some selected villages of Bangladesh. Bangladesh Veterinarian, 7:45-47.

MADSEN, H., DAFFALLA, A.A., KAROUM, K.O. \& FRANDSEN, F. 1988. Distribution of freshwater snails in irrigation schemes in the Sudan. Journal of Applied Ecology, 25:853866.

MAHATO, S.N. \& RAI, K. 1992. Prevalence of amphistomosis in cattle in the Koshi zone of Nepal. Veterinary Review Kathmandu, 7:63-64.

MARGOLIS, L., ESCH, G.W., HOLMES, J.C., KURIS, A.M. \& SCHAD, G.A. 1982. The use of ecological terms in parasitology, (Report on an ad hoc committee of the American
Society of Parasitologists). Journal of Parasitology, 68:131133.

MAVENYENGWA, M. 2004. Pathophysiology of Calicophoron microbothrium in experimentally infected cattle and the effect of challenge infection. D.Phil thesis. University of Zimbabwe.

MUKARATIRWA, S., SIEGISMUND, H.R., KRISTENSEN, T.K. \& CHANDIWANA, S.K. 1996. Population genetics and genetic variability of Bulinus globosus (Gastropoda: Plarnorbidae) from the two main river systems in Zimbabwe. Journal of Heredity, 87:288-294.

MUKARATIRWA, S., KRISTENSEN, T.K., SIEGISMUND, H.R. \& CHANDIWANA, S.K. 1998. Genetic and morphological variation of populations belonging to the Bulinus tropicus/ truncatus complex (Gastropoda: Plarnorbidae) in Southwestern Zimbabwe. Journal of Molluscan Studies, 64:435446.

OKAFOR, F.C., MBATA, G. \& ANOSIKE, J. 1988. Studies on Paramphistomum cervi (Schrank, 1790) infections of ruminants in Imo State, Nigeria with special reference to role played by Bulinus b. forskalii (Ehrenberg) in their transmission. Bulletin of Animal Health and Production in Africa, 36: 142-146.

ROLFE, P.F. \& BORAY, J.C. 1987. Chemotherapy of amphistomosis in cattle. Australia Veterinary Journal, 64:328-332.

ROLFE, P.F., BORAY, J.C., NICHOLS, P. \& COLLINS, G.H. 1991. Epidemiology of amphistomosis in cattle. International Journal of Parasitology, 21:813-819.

SAHAY, M.N., SAHAI, B.N. \& SINGH, S.K. 1989. Survey of amphistome infection in bovine: its seasonal and regional variations in the state of Bihar (India). Indian Journal of Animal Health, 28:91-98.

SEY, O. 1991. CRC Handbook of the zoology of amphistomes. Boca Raton: CRC Press Inc.

SWART, P.J. \& REINECKE, R.K. 1962a. Studies on paramphistomiasis. 1. The propagation of Bulinus tropicus Krauss 1848. Onderstepoort Journal of Veterinary Research, 29: 183-187.

SWART, P.J. \& REINECKE, R.K. 1962b. Studies on paramphistomiasis. 11. The mass production of metacercariae of Paramphistomum microbothrium Fischoeder 1901. Onderstepoort Journal of Veterinary Research, 29:189-195.

THOMAS, J.D. 1982. Chemical ecology of the snail hosts of schistosomiasis: snail-snail and snail-plant interactions. Malacologia, 22:81-91.

VASSILEV, G.D. 1994. Prevalence and seasonality of internal parasite infections detectable by faecal examination of cattle in Chiweshe communal farming area of Zimbabwe. Zimbabwe Veterinary Journal, 25:41-63.

VASSILEV, G.D. 1999. Prevalence of internal parasite infections of cattle in the communal farming areas of Mashonaland East Province, Zimbabwe. Zimbabwe Veterinary Journal, 30:1-17.

VATTA, A.F. \& KRECEK, R.C. 2002. Amphistome infection of goats farmed under resource-poor conditions in South Africa. Onderstepoort Journal of Veterinary Research, 69: 327-329.

WOOLHOUSE, M.E.J. \& CHANDIWANA, S.K. 1990. Population biology of the freshwater snail Bulinus globosus in the Zimbabwe highveld. Journal of Applied Ecology, 27:41-59.

WRIGHT, C.A., SOUTHGATE, V.R. \& HOWARD, G.W. 1979. A note on the life cycles of some amphistome flukes in Zambia. Journal of Helminthology, 53:251-252. 